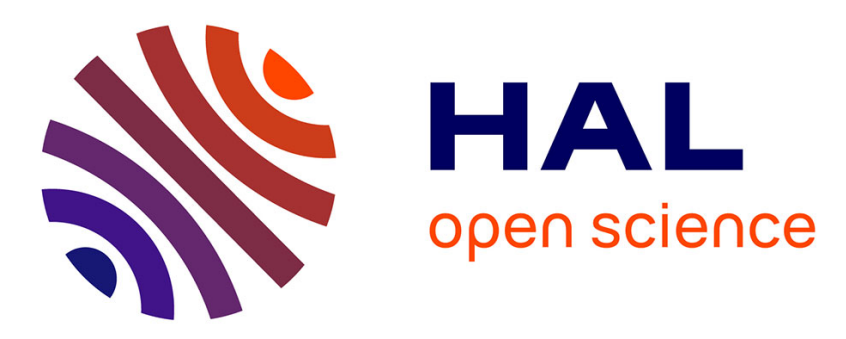

\title{
Electroluminescence efficiencies of erbium in silicon-based hosts
}

Sébastien Cueff, Joan Manel Ramirez, Jonathan Kurvits, Yonder Berencen, Rashid Zia, B. Garrido, Richard Rizk, Christophe Labbe

\section{- To cite this version:}

Sébastien Cueff, Joan Manel Ramirez, Jonathan Kurvits, Yonder Berencen, Rashid Zia, et al.. Electroluminescence efficiencies of erbium in silicon-based hosts. Applied Physics Letters, 2013, 103, pp.191109. 10.1063/1.4829142 . hal-01146452

\section{HAL Id: hal-01146452 \\ https://hal.science/hal-01146452}

Submitted on 28 Apr 2015

HAL is a multi-disciplinary open access archive for the deposit and dissemination of scientific research documents, whether they are published or not. The documents may come from teaching and research institutions in France or abroad, or from public or private research centers.
L'archive ouverte pluridisciplinaire HAL, est destinée au dépôt et à la diffusion de documents scientifiques de niveau recherche, publiés ou non, émanant des établissements d'enseignement et de recherche français ou étrangers, des laboratoires publics ou privés. 


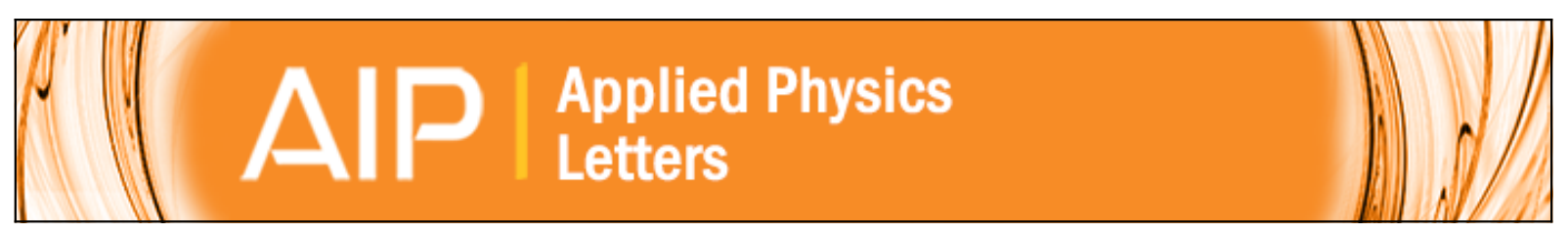

\section{Electroluminescence efficiencies of erbium in silicon-based hosts}

Sébastien Cueff, Joan Manel Ramírez, Jonathan A. Kurvits, Yonder Berencén, Rashid Zia, Blas Garrido,

Richard Rizk, and Christophe Labbé

Citation: Applied Physics Letters 103, 191109 (2013); doi: 10.1063/1.4829142

View online: http://dx.doi.org/10.1063/1.4829142

View Table of Contents: http://scitation.aip.org/content/aip/journal/apl/103/19?ver=pdfcov

Published by the AIP Publishing

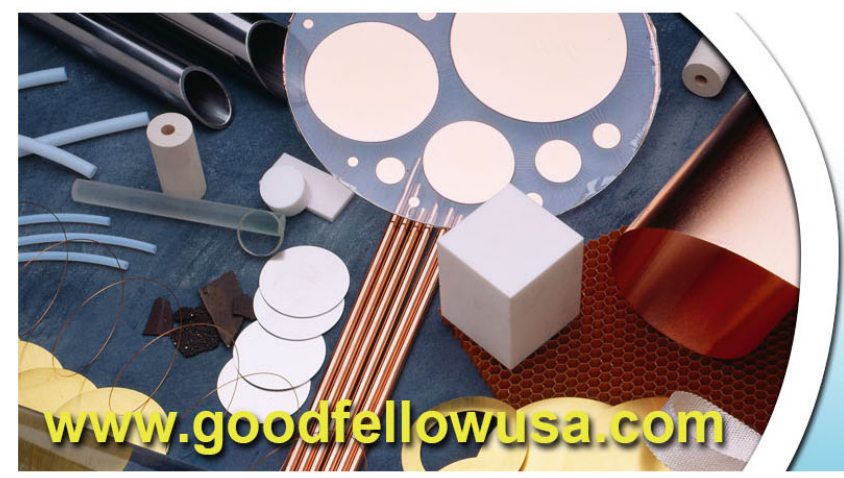

BDOdFE//II

metals • ceramics $\cdot$ polymers composites • compounds • glasses

Save $5 \% \cdot$ Buy online 70,000 products $\cdot$ Fast shipping 


\title{
Electroluminescence efficiencies of erbium in silicon-based hosts
}

\author{
Sébastien Cueff, ${ }^{1,2, a), b)}$ Joan Manel Ramírez, ${ }^{3, a)}$ Jonathan A. Kurvits, ${ }^{2,4}$ Yonder Berencén, ${ }^{3}$ \\ Rashid Zia, ${ }^{2,4}$ Blas Garrido, ${ }^{3}$ Richard Rizk, ${ }^{1}$ and Christophe Labbé ${ }^{1, b)}$ \\ ${ }^{1}$ Centre de Recherche sur les Ions, les Matériaux et la Photonique (CIMAP), \\ UMR 6252 CNRS/CEA/Ensicaen/UCBN, Caen 14050, France \\ ${ }^{2}$ School of Engineering, Brown University, Providence, Rhode Island 02912, USA \\ ${ }^{3}$ MIND-IN2UB, Department Electrònica, Universitat de Barcelona, Martí i Franquès 1, \\ Barcelona 08028, Spain \\ ${ }^{4}$ Department of Physics, Brown University, Providence, Rhode Island 02912, USA
}

(Received 26 July 2013; accepted 17 October 2013; published online 6 November 2013)

We report on room-temperature $1.5 \mu \mathrm{m}$ electroluminescence from trivalent erbium $\left(\mathrm{Er}^{3+}\right)$ ions embedded in three different CMOS-compatible silicon-based hosts: $\mathrm{SiO}_{2}, \mathrm{Si}_{3} \mathrm{~N}_{4}$, and $\mathrm{SiN}_{\mathrm{x}}$. We show that although the insertion of either nitrogen or excess silicon helps enhance electrical conduction and reduce the onset voltage for electroluminescence, it drastically decreases the external quantum efficiency of $\mathrm{Er}^{3+}$ ions from $2 \%$ in $\mathrm{SiO}_{2}$ to $0.001 \%$ and $0.0004 \%$ in $\mathrm{SiN}_{\mathrm{x}}$ and $\mathrm{Si}_{3} \mathrm{~N}_{4}$, respectively. Furthermore, we present strong evidence that hot carrier injection is significantly more efficient than defect-assisted conduction for the electrical excitation of $\mathrm{Er}^{3+}$ ions. These results suggest strategies to optimize the engineering of on-chip electrically excited silicon-based nanophotonic light sources. (C) 2013 AIP Publishing LLC. [http://dx.doi.org/10.1063/1.4829142]

Research towards fabricating efficient electrically driven silicon-based light sources holds promise for the full integration of nanophotonics with microelectronics on a silicon chip. ${ }^{1}$ To circumvent the intrinsically low photon emission probability in silicon, researchers have investigated methods to dope silicon-based host materials with more efficient light emitters. ${ }^{2-4}$ For this purpose, $\mathrm{Er}^{3+}$ ions have attracted considerable interest because their near-infrared $1.5 \mu \mathrm{m}$ emission coincides with the "C-band" of optical telecommunication. ${ }^{5}$ In silicon though, $\mathrm{Er}^{3+}$ ions undergo significant thermal quenching due to non-radiative energy back-transfer to the host matrix. ${ }^{3}$ Strategies to avoid such electronic back-transfer consist of using large bandgap silicon-based hosts such as $\mathrm{SiO}_{2}$ or $\mathrm{Si}_{3} \mathrm{~N}_{4}$. While these latter host materials were shown to be a good platform for $\mathrm{Er}^{3+}$ photoluminescence, their insulating properties impede carrier injection and transport for electrically-driven devices.

To address this electrical challenge, researchers have sought to embed $\mathrm{Er}^{3+}$ ions in engineered host materials that allow for efficient injection of carriers at low operating voltages. For example, recent studies investigated the influence of host composition on the electroluminescence (EL) properties of $\mathrm{Er}^{3+}: \mathrm{SiN}_{\mathrm{x}}$ (Ref. 6) and $\mathrm{Er}^{3+}: \mathrm{SiO}_{\mathrm{x}}$ (Refs. 7-9) as well as other oxide hosts such as $\mathrm{Er}^{3+}: \mathrm{TiO}_{2}$ (Ref. 10) and $\mathrm{Er}^{3+}: \mathrm{ZnO} .^{11,12}$ However, it can be difficult to interpret and resolve the conflicting results reported in the literature because of the disparities in electrical and optical properties between different hosts as well as the fabrication-dependent properties observed for similar materials. ${ }^{13,14}$

In this letter, we report on a systematic comparison of several figures of merit for $\mathrm{Er}^{3+} \mathrm{EL}$ in different silicon-based CMOS-compatible hosts. To this end, we investigate the

\footnotetext{
${ }^{\text {a) }}$ S. Cueff and J. M. Ramírez contributed equally to this work

b) Authors to whom correspondence should be addressed. Electronic addresses: sebastien_cueff@brown.edu and christophe.labbe@ensicaen.fr
}

electrical and optical properties of Er-doped electroluminescent devices fabricated with three distinct hosts for the active layer: silicon dioxide $\left(\mathrm{SiO}_{2}\right)$, silicon nitride $\left(\mathrm{Si}_{3} \mathrm{~N}_{4}\right)$, and silicon-rich nitride $\left(\mathrm{SiN}_{\mathrm{x}}\right)$. By using the same fabrication equipment, processing techniques, and device geometry (e.g., emitter layer thickness and area) for all samples, we seek to isolate the host material dependencies of the Er-doped active layers. While all devices display $1.5 \mu \mathrm{m}$ emission under electrical injection, we show that their respective properties such as external quantum efficiency, electrical transport characteristics, and excitation cross-sections significantly differ, sometimes by orders of magnitude.

The Er-doped Si-based active layers were all deposited by the same confocal magnetron sputtering equipment at high substrate temperature $\left(500^{\circ} \mathrm{C}\right) .{ }^{15}$ Near stoichiometric $\mathrm{Er}^{3+}: \mathrm{SiO}_{2}$ and $\mathrm{Er}^{3+}: \mathrm{Si}_{3} \mathrm{~N}_{4}$ were produced by cosputtering from $\mathrm{Er}_{2} \mathrm{O}_{3}$ and either $\mathrm{SiO}_{2}$ or $\mathrm{Si}_{3} \mathrm{~N}_{4}$ targets under a plasma of pure argon. $\mathrm{Er}^{3+}: \mathrm{SiN}_{\mathrm{x}}$ was grown using reactive sputtering by flowing $0.6 \mathrm{sccm}$ of nitrogen and $10 \mathrm{sccm}$ of argon inside the chamber during cosputtering of $\mathrm{Si}$ and $\mathrm{Er}_{2} \mathrm{O}_{3}$ targets. The resulting $\mathrm{SiN}_{\mathrm{x}}$ host is silicon-rich with $\mathrm{x} \approx 0.8{ }^{16}$ All active layers are $50 \mathrm{~nm}$-thick and deposited on a p-type silicon substrate $\left(1 \times 10^{15}\right.$ at. $\left./ \mathrm{cm}^{3}\right)$. The Er concentration, as measured by secondary ion mass spectrometry (SIMS), was typically found to be around $[\mathrm{Er}]=1 \times 10^{20} \mathrm{~cm}^{-3}$. A heavily doped $\left(1 \times 10^{20} \mathrm{~cm}^{-3}\right) 100$-nm thick $\mathrm{n}^{+}$-polysilicon top electrode is subsequently deposited directly on top of the active layer by low pressure chemical vapor deposition (LPCVD). The devices are then post-annealed at $950^{\circ} \mathrm{C}$ for 30 min under pure $\mathrm{N}_{2}$. To form electrical contacts, aluminum and chromium were deposited on the top and bottom of the structure, respectively; the top aluminum contacts were patterned in the shape of isolated squares $(200 \mu \mathrm{m}$ by $200 \mu \mathrm{m})$ with empty square center ( $60 \mu \mathrm{m}$ by $60 \mu \mathrm{m}$ ) to allow for efficient electrical excitation and light extraction (a sketch of the device is shown inset of Fig. 1(a)). All electro-optical 
experiments were performed under forward bias (i.e., negative voltage applied to the polysilicon electrode) allowing higher current to flow through the active layer. A probe station and a semiconductor device analyzer were used to monitor I-V characteristics. The electroluminescence signal was collected from the top half of the device through the Si electrode by a microscope objective (NA: 0.4). For spectral analysis, the light was dispersed by a spectrograph and measured with a calibrated photomultiplier tube (PMT). Time-resolved measurements were carried out using a pulse generator, and EL decay traces were recorded with a digital $\mathrm{GHz}$ oscilloscope connected to the PMT.

Figure 1 displays both the current density and the EL signals of the three layers investigated as a function of the applied voltage (until reaching the electrical breakdown of the active layer). A typical EL spectrum is displayed in the inset of Fig. 1(b); the EL spectrum for all samples showed a similar line shape. One can readily observe a clear trend in the electrical properties when nitrogen is introduced and when Si-excess content is increased: as shown in Fig. 1(a), the threshold voltage is decreased, and the maximum current density is enhanced. Consequently, as shown in Fig. 1(b), the onset voltage for EL is strongly reduced, from $\sim 45 \mathrm{~V}$ to
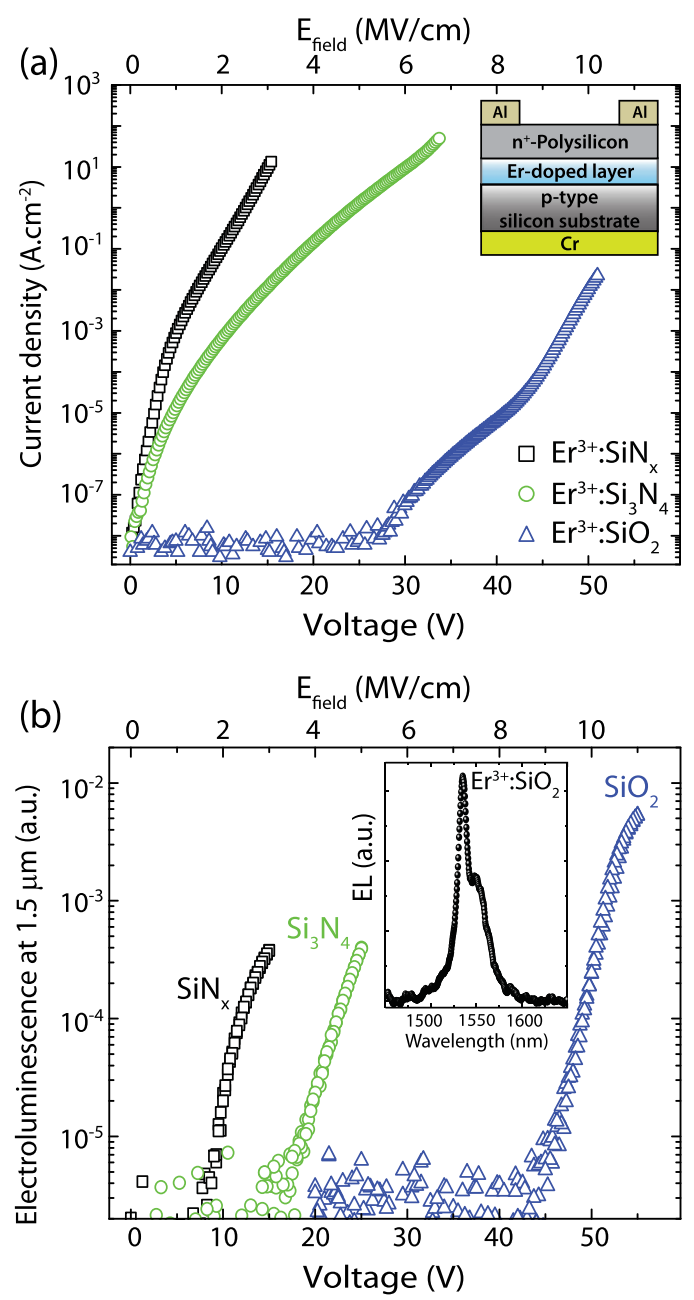

FIG. 1. (a) Current density as a function of the applied voltage for $\mathrm{Er}^{3+}: \mathrm{SiN}_{\mathrm{x}}, \mathrm{Er}^{3+}: \mathrm{Si}_{3} \mathrm{~N}_{4}$, and $\mathrm{Er}^{3+}: \mathrm{SiO}_{2}$. Inset: scheme of the device's geometry. (b) Electroluminescence intensity at $1.5 \mu \mathrm{m}$ for the same devices as a function of the applied voltage. Inset: typical EL spectrum obtained (only $\mathrm{Er}^{3+}: \mathrm{SiO}_{2}$ is displayed for clarity). $\sim 7 \mathrm{~V}$, when the composition of the host changes from $\mathrm{SiO}_{2}$ to $\mathrm{SiN}_{\mathrm{x}}$. However, a collateral effect is that the maximum EL intensity is reduced by around one order of magnitude. At this stage, it is unclear whether it is due to the observed disparities in breakdown voltages or to intrinsic differences in the active layers' properties, and we therefore provide in the following a thorough investigation of the underlying physical mechanisms involved in this process.

A typical figure of merit for electroluminescence efficacy is external quantum efficiency (EQE), which is given by the ratio between emitted photons and injected electrons. Using a calibrated PMT, the EQE values were obtained as a function of current density. As shown in Figure 2, the EQE of $\mathrm{Er}^{3+}: \mathrm{SiO}_{2}(2 \%)$ is three orders of magnitude higher than those of $\mathrm{Er}^{3+}: \operatorname{SiN}_{\mathrm{x}}\left(10^{-3} \%\right)$ and $\mathrm{Er}^{3+}: \mathrm{Si}_{3} \mathrm{~N}_{4}\left(4 \times 10^{-4} \%\right)$. Although all fabricated electroluminescent devices have identical device geometries, the material into which $\mathrm{Er}^{3+}$ ions are embedded alters the coupling to radiative modes through two effects: (i) changes in the local field around $\mathrm{Er}^{3+}$ and (ii) modification of the Fresnel coefficients at the interfaces. ${ }^{17-20}$ These combined effects imply that increasing the host refractive index should enhance the power radiated to the upper half space of the structure and thus collected by our detection system (see supplementary material ${ }^{21}$ ). This trend is not observed in our measurements, in which the lowest refractive index $\left(\mathrm{n}_{\mathrm{SiO} 2}=1.5\right)$ yields the highest EQE. Such a statement indicates that the differences in the measured EQE do not arise from optical effects caused by the change of refractive index but rather from different excitation efficiencies. Further insight is given hereafter through analysis of both electrical transport and excitation cross sections of the $\mathrm{Er}^{3+}$ ions.

Due to the dielectric and amorphous character of the active medium, the electrical transport of carriers in such insulating layers typically shows a non-Ohmic behavior. To describe the conduction properties, a whole range of models are available in the literature among which the most commonly reported are Fowler-Nordheim Tunneling ${ }^{22}$ (FNT) and Poole-Frenkel (PF) thermionic emission. ${ }^{23}$ As displayed in Figure 3, we find that the electrical transport in nitridebased layers is a bulk-limited process assisted by localized

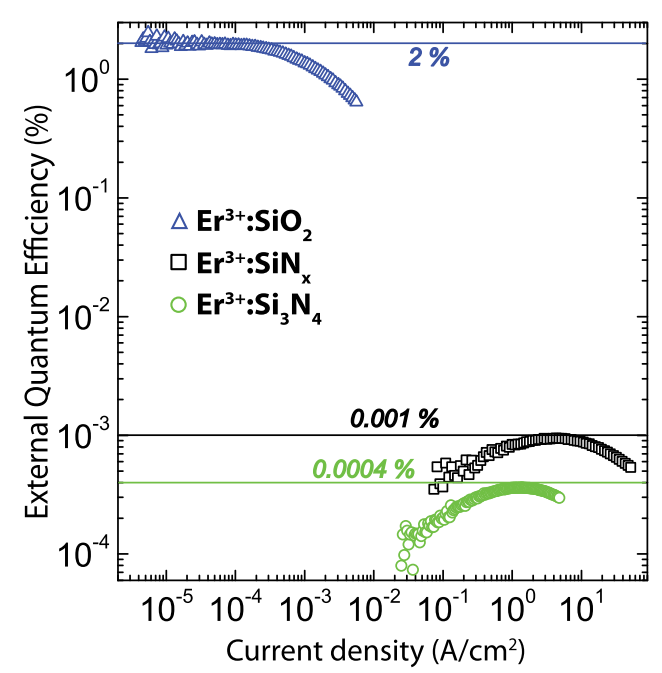

FIG. 2. EQE for the near-infrared emission $(1.3 \mu \mathrm{m}-1.6 \mu \mathrm{m})$ as a function of injected current for the three investigated light emitting devices. 


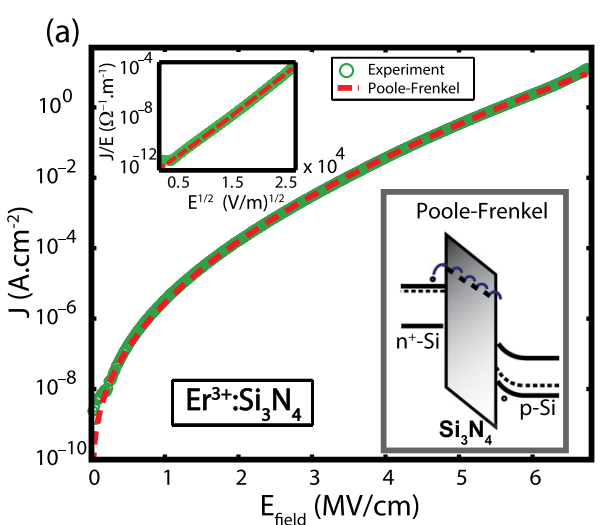

(c)

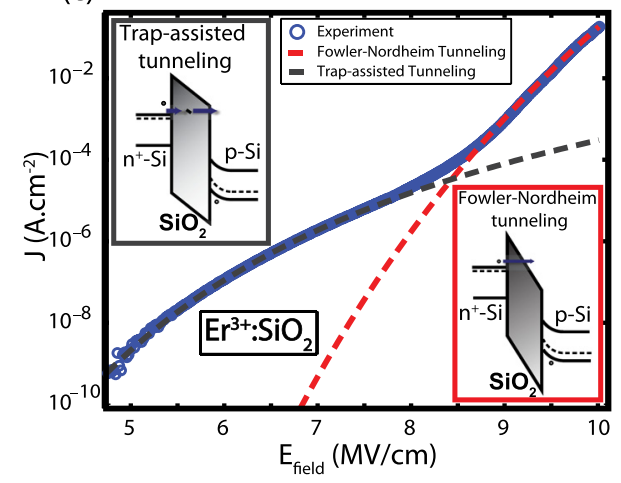

(b)

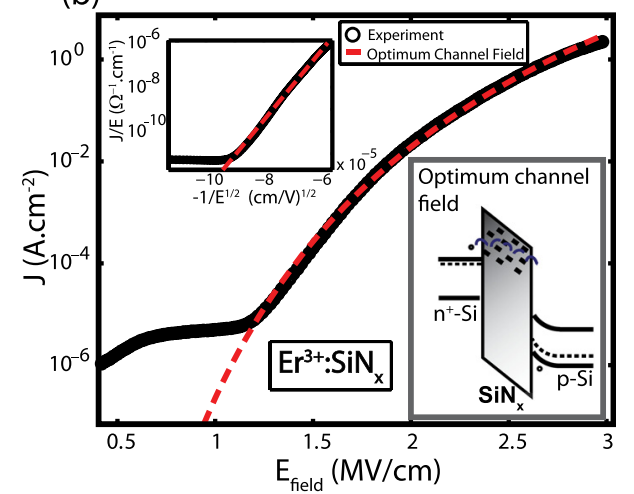

(d)

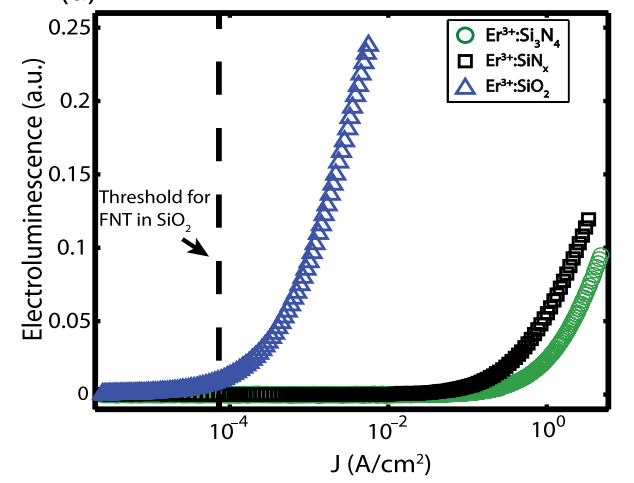

FIG. 3. Current density-electric field (J-E) characteristics response of (a) $\mathrm{Er}^{3+}: \mathrm{Si}_{3} \mathrm{~N}_{4}$, (b) $\mathrm{Er}^{3+}: \mathrm{SiN}_{\mathrm{x}}$, and (c) $\mathrm{Er}^{3+}: \mathrm{SiO}_{2}$ together with fits from theoretical models. Insets: schematics highlighting the modeled conduction mechanisms. (d) Electroluminescence signal at $1.5 \mu \mathrm{m}$ as a function of current density. states in the bandgap, consistent with a previous study. ${ }^{24}$ Specifically, the J-E curves are best described by PF conduction $^{25}$ and optimum-channel field emission ${ }^{26,27}$ for $\mathrm{Er}^{3+}: \mathrm{Si}_{3} \mathrm{~N}_{4}$ and $\mathrm{Er}^{3+}: \mathrm{SiN}_{\mathrm{x}}$, respectively (more information in the supplementary material ${ }^{21}$ ). On the other hand, the electrical transport in $\mathrm{SiO}_{2}$ is first enabled by trap-assisted tunneling (from 5 to $8 \mathrm{MV} / \mathrm{cm}$ ) and subsequently followed by hot carrier injection due to FNT mechanism at high fields (greater than $8 \mathrm{MV} / \mathrm{cm}$ ). Interestingly in this latter case, the resulting EL signal starts to be significant only after reaching the FNT regime (see Fig. 3(d)). This suggests that the injection of hot electrons in the conduction band is a more efficient process for the excitation of $\mathrm{Er}^{3+}$ ions than trap-assisted conduction.

The excitation cross section of $\mathrm{Er}^{3+}$ ions is a key parameter to understand the efficiency of the excitation process under electrical pumping. $\mathrm{Er}^{3+}$ ions comprise numerous excited states that usually require a detailed set of rate equations to provide accurate modeling of the electronic transitions. ${ }^{28}$ However, in the low pump regime, two reasonable assumptions can be made: (i) non-radiative relaxation from higher lying states is much faster than the long relaxation from ${ }^{4} \mathrm{I}_{13 / 2}$ level and (ii) there are no non-linear processes (e.g., excited state absorption or energy transfer between ions). At low current flux, we can therefore model the system under study as a quasi-two-level-system even if the excitation occurs at higher-lying states (see supplementary material $\left.^{21}\right) .{ }^{29}$ Therefore, in the steady-state regime, the electroluminescence intensity is described by $E L=\frac{\sigma_{\bar{q}}^{I} \tau}{\sigma_{\bar{q}}^{\sigma} \tau+1} E L_{\max } \cdot{ }^{30} \mathrm{By}$ measuring separately the lifetime $\tau$ of our samples, the excitation cross-section $\sigma$ can be extracted by fitting the measured EL signal as a function of the current flux $(\mathrm{J} / \mathrm{q})$. It is found that the $\sigma$ values for $\mathrm{Er}^{3+}: \mathrm{Si}_{3} \mathrm{~N}_{4}, \mathrm{Er}^{3+}: \mathrm{SiN}_{\mathrm{x}}$, and $\mathrm{Er}^{3+}: \mathrm{SiO}_{2}$ are $3 \times 10^{-16} \mathrm{~cm}^{2}, 1 \times 10^{-15} \mathrm{~cm}^{2}$, and $3 \times 10^{-14} \mathrm{~cm}^{2}$, respectively (cf., Fig. 4). Similar values were already reported for $\mathrm{Er}^{3+}: \mathrm{SiN}_{\mathrm{x}}{ }^{6}$ and the $\sigma$ for $\mathrm{Er}^{3+}: \mathrm{SiO}_{2}$ is among the highest excitation cross-sections reported in the literature. 8,31 Comparable range of $\sigma$ values can be obtained by investigating the dynamics of EL intensity of our samples (see supplementary material $^{21}$ ).

To have an independent confirmation of the differences in excitation efficiency, we provide an evaluation of the number of excited $\mathrm{Er}^{3+}$ ions in each sample. One can roughly estimate a lower bound for the fraction of electrically excited $\mathrm{Er}^{3+}$ ions by using the following relation ${ }^{7}$ : $\frac{N_{E r}^{*}}{[E r]}=A \frac{W_{o p t} \tau}{h v S d}$, where $A$ is a correction factor that takes into account both the total transmittance at $1.5 \mu \mathrm{m}$ through the top polysilicon layer and the collection of the detection system (these combined effects reduce the detected power to $2 \%$ of the total emitted power for all investigated layers), $W_{\text {opt }}$ is the detected optical power, $\tau$ the measured lifetime, $h v$ the energy of light emission, $S$ the emitting area, and $d$ the thickness of the active layer. While the fraction of excited $\mathrm{Er}^{3+}$ ions for $\mathrm{SiN}_{\mathrm{x}}$ and $\mathrm{Si}_{3} \mathrm{~N}_{4}$ are found to be $0.08 \%$ and $0.09 \%$, respectively, it is significantly higher in $\mathrm{SiO}_{2}$ for which it is estimated to be around $15 \%$. Although potential clustering of erbium could limit the light emission in some cases, ${ }^{32}$ such a phenomenon would affect all samples equally as the same fabrication process and thermal treatment were used for all devices. Furthermore, we can infer on the basis of lifetime evolution versus current flux that nonlinear effects such as energy transfer could occur at high flux in $\mathrm{Si}_{3} \mathrm{~N}_{4}$ but neither in $\mathrm{SiN}_{\mathrm{x}}$ nor in $\mathrm{SiO}_{2}$ (see supplementary material $^{21}$ ). This phenomenon is therefore not responsible for the large differences in efficiencies between nitride and oxide hosts. 

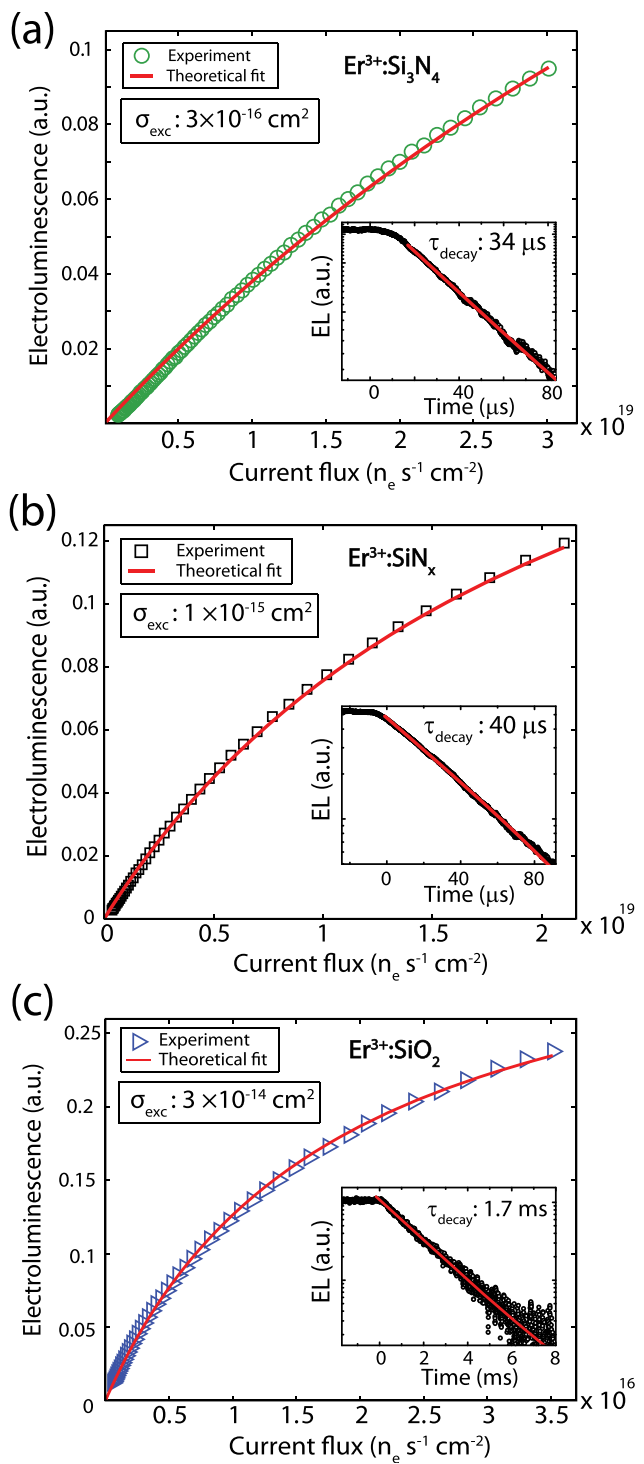

FIG. 4. Electroluminescence signal as a function of current flux for (a) $\mathrm{Er}^{3+}: \mathrm{Si}_{3} \mathrm{~N}_{4}$, (b) $\mathrm{Er}^{3+}: \mathrm{SiN}_{\mathrm{x}}$, and (c) $\mathrm{Er}^{3+}: \mathrm{SiO}_{2}$ along with their corresponding theoretical fits to extract values of excitation cross-sections. Insets: measured lifetimes and fits.

Note that the low number of excited $\mathrm{Er}^{3+}$ ions in nitrogen-containing electroluminescent devices $\left(\mathrm{Si}_{3} \mathrm{~N}_{4}\right.$ and $\mathrm{SiN}_{\mathrm{x}}$ ) is correlated with the bulk-limited conduction mechanism in these materials. While this process allows for good conduction properties and low onset voltage for EL, it strongly reduces the excitation efficiency of $\mathrm{Er}^{3+}$ ions. In such a regime, the $\mathrm{Er}^{3+}$ excitation could occur via either energy transfer between traps and $\mathrm{Er}^{3+}$ ions ${ }^{6,8,10-12}$ or impact excitation. ${ }^{8}$ In the case of energy-transfer excitation, the donor-acceptor interaction is distance-dependent, ${ }^{33}$ and the probability for such a process to occur is therefore low (Note that the fraction of excited $\mathrm{Er}^{3+}$ ions found here is comparable to the one for $\mathrm{Er}^{3+}$ ions sensitized by energy-transfer from $\mathrm{Si}$ nanoclusters. ${ }^{33,34}$ ) On the other hand, potential impact excitation of $\mathrm{Er}^{3+}$ would require the injection of hot electrons having energies higher than the first excited state of $\mathrm{Er}^{3+}(0.8 \mathrm{eV})$. As measured by DiMaria et al., the number of injected hot electrons in nitride-based layers is almost four-orders of magnitude lower than in a similar $\mathrm{SiO}_{2}$ layer because of electrical trapping. ${ }^{35}$ Indeed, although FNT transport of carriers in $\mathrm{SiO}_{2}$ yields a relatively low conductivity, it ensures the injection of a high number of hot carriers. 35,36 Besides, as shown by Fischetti et al. ${ }^{36}$ in the range of electric fields applied in the present study $(8-10 \mathrm{MV} / \mathrm{cm})$, the energy of hot electrons in $\mathrm{SiO}_{2}$ is distributed over an average value of around $3 \mathrm{eV}$, i.e., more than enough to pump the $\mathrm{Er}^{3+}$ ions to the first excited state by impact excitation. The significantly higher number of injected hot electrons in $\mathrm{SiO}_{2}$ compared to nitride-based layers provides a straightforward explanation of the large differences in excitation cross sections and in the number of excited $\mathrm{Er}^{3+}$ ions. Interestingly, these correlations between electrical transport and excitation efficiencies can be inferred from the $\mathrm{Er}^{3+}: \mathrm{SiO}_{2}$ sample alone because it demonstrates both types of conduction mechanisms. Indeed the abrupt increase in $\mathrm{Er}^{3+} \mathrm{EL}$ as soon as the FNT regime starts (Fig. 3(d)) provides a direct and striking confirmation of the higher efficiency of the hot carrier injection as compared to defect-assisted conduction for the excitation of $\mathrm{Er}^{3+}$ ions.

In conclusion, we have demonstrated that although both electrical conduction and onset voltage for the electroluminescence of $\mathrm{Er}^{3+}$ are greatly enhanced in nitrogen-containing Si-based samples, their excitation efficiencies are well below that of $\mathrm{Er}^{3+}: \mathrm{SiO}_{2}$. These results suggest that defect-assisted transport of carriers is a much less efficient process than hot electron injection for the electrical excitation of $\mathrm{Er}^{3+}$. Despite the large excitation cross sections and EQE values for $\mathrm{EL}$ in $\mathrm{Er}^{3+}: \mathrm{SiO}_{2}$ electroluminescent devices, their very high onset voltage remains largely incompatible with current CMOS technology. On the other hand, the extremely low onset voltage for $\mathrm{EL}$ in $\mathrm{Er}^{3+}: \mathrm{SiN}_{\mathrm{x}}$ appears very promising. Therefore, future studies should focus on electrical and material engineering to combine the advantages of both hosts to efficiently inject hot carriers at low voltages. In this framework, heterostructures composed of nanometer-thick multilayers appear to be a promising direction for investigation. ${ }^{37}$

The authors thank C. M. Dodson, M. Jiang, S. Karaveli, and D. Li for helpful discussions and C. Frilay for technical assistance. We acknowledge the Instituto de Microelectronica de Barcelona (IMB-CNM, CSIC) and especially J. Montserrat and C. Domínguez for the sample processing. Financial support was provided, in part, by the Air Force Office of Scientific Research (PECASE award no. FA-9550-10-1-0026) and by the National Science Foundation (CAREER award no. EECS-0846466). J.M.R. thanks the financial support of AGAUR through the program FI-DGR 2013.

${ }^{1}$ B. Jalali and S. Fathpour, J. Lightwave Technol. 24, 4600 (2006).

${ }^{2}$ B. Zheng, J. Michel, F. Y. G. Ren, L. C. Kimerling, D. C. Jacobson, and J. M. Poate, Appl. Phys. Lett. 64, 2842 (1994).

${ }^{3}$ A. J. Kenyon, Prog. Quantum Electron. 26, 225 (2002).

${ }^{4}$ L. Pavesi, L. Dal Negro, C. Mazzoleni, G. Franzo, and F. Priolo, Nature 408, 440 (2000).

${ }^{5}$ J. F. M. Digonnet, Rare-Earth-Doped Fiber Lasers and Amplifiers, Revised and Expanded (CRC Press, 2002), p. 71.

${ }^{6}$ S. Yerci, R. Li, and L. Dal Negro, Appl. Phys. Lett. 97, 081109 (2010).

${ }^{7}$ O. Jambois, F. Gourbilleau, A. J. Kenyon, J. Montserrat, R. Rizk, and B. Garrido, Opt. Express 18, 2230 (2010).

${ }^{8}$ J. M. Ramírez, F. Ferrarese Lupi, O. Jambois, Y. Berencén, D. NavarroUrrios, A. Anopchenko, A. Marconi, N. Prtljaga, A. Tengattini, L. Pavesi, 
J. P. Colonna, J. M. Fedeli, and B. Garrido, Nanotechnology 23, 125203 (2012).

${ }^{9}$ S. Cueff, C. Labbé, O. Jambois, Y. Berencén, A. J. Kenyon, B. Garrido, and R. Rizk, Opt. Express 20, 22490 (2012).

${ }^{10}$ Y. Yang, L. Jin, X. Y. Ma, and D. R. Yang, Appl. Phys. Lett. 100, 031103 (2012).

${ }^{11}$ E. F. Pecora, T. I. Murphy, and L. D. Negro, Appl. Phys. Lett. 101, 191115 (2012).

${ }^{12}$ Y. Yang, Y. Li, L. Xiang, X. Ma, and D. Yang, Appl. Phys. Lett. 102, 181111 (2013).

${ }^{13}$ A. Nazarov, J. M. Sun, W. Skorupa, R. A. Yankov, I. N. Osiyuk, I. P. Tjagulskii, V. S. Lysenko, and T. Gebel, Appl. Phys. Lett. 86, 151914 (2005).

${ }^{14}$ K. Sun, W. J. Xu, B. Zhang, L. P. You, G. Z. Ran, and G. G. Qin, Nanotechnology 19, 105708 (2008).

${ }^{15}$ S. Cueff, C. Labbé, J. Cardin, J.-L. Doualan, L. Khomenkova, K. Hijazi, O. Jambois, B. Garrido, and R. Rizk, J. Appl. Phys. 108, 064302 (2010); S. Cueff, C. Labbé, J. Cardin, and R. Rizk, IOP Conf. Ser.: Mater. Sci. Eng. 6, 012021 (2009).

${ }^{16}$ S. Cueff, C. Labbé, L. Khomenkova, O. Jambois, P. Pellegrino, B. Garrido, C. Frilay, and R. Rizk, Mater. Sci. Eng. B 177, 725 (2012).

${ }^{17}$ G. L. J. A. Rikken and Y. A. R. R. Kessener, Phys. Rev. Lett. 74, 880 (1995).

${ }^{18}$ C. M. Dodson and R. Zia, Phys. Rev. B 86, 125102 (2012).

${ }^{19}$ R. J. Glauber and M. Lewenstein, Phys. Rev. A 43, 467 (1991).

${ }^{20}$ L. Zampedri, M. Mattarelli, M. Montagna, and R. R.Goncalves, Phys. Rev. B 75, 073105 (2007).

${ }^{21}$ See supplementary material at http://dx.doi.org/10.1063/1.4829142 for calculation of power radiated, analysis of the electrical properties, and electroluminescence dynamics.

${ }^{22}$ R. H. Fowler and L. W. Nordheim, Proc. R. Soc. London, Ser. A 119, 173 (1928).
${ }^{23}$ J. Frenkel, Tech. Phys. USSR 5, 685 (1938); Phys. Rev. 54, 647 (1938).

${ }^{24}$ Y. Berencén, J. M. Ramírez, and B. Garrido, in Proceedings of the 2013 Spanish Conference on Electron Devices, CDE 2013 (IEEE Xplore, Valladolid, 2013).

${ }^{25}$ M. Ieda, G. Sawa, and S. Kato, J. Appl. Phys. 42, 3737 (1971).

${ }^{26}$ M. Pollak and J. J. Hauser, Phys. Rev. Lett. 31, 1304 (1973).

${ }^{27}$ M. Nardone, M. Simon, I. V. Karpov, and V. G. Karpov, J. Appl. Phys. 112, 071101 (2012).

${ }^{28}$ D. Pacifici, G. Franzò, F. Priolo, F. Iacona, and L. Dal Negro, Phys. Rev. B 67, 245301 (2003).

${ }^{29}$ A. J. Kenyon, M. Wojdak, I. Ahmad, W. H. Loh, and C. J. Oton, Phys. Rev. B 77, 035318 (2008).

${ }^{30}$ S. Coffa, G. Franzó, and F. Priolo, Appl. Phys. Lett. 69, 2077 (1996).

${ }^{31}$ F. Iacona, D. Pacifici, A. Irrera, M. Miritello, G. Franzò, F. Priolo, D. Sanfilippo, G. Di Stefano, and P. G. Fallica, Appl. Phys. Lett. 81, 3242 (2002).

${ }^{32}$ N. Prtljaga, D. Navarro-Urrios, A. Tengattini, A. Anopchenko, J. M. Ramírez, J. M. Rebled, S. Estradé, J.-P. Colonna, J.-M. Fedeli, B. Garrido, and L. Pavesi, Opt. Mater. Express 2, 1278 (2012).

${ }^{33}$ B. Garrido, C. García, S.-Y. Seo, P. Pellegrino, D. Navarro-Urrios, N. Daldosso, L. Pavesi, F. Gourbilleau, and R. Rizk, Phys. Rev. B 76, 245308 (2007).

${ }^{34}$ M. Wojdak, M. Klik, M. Forcales, O. B. Gusev, T. Gregorkiewicz, D. Pacifici, G. Franzo, F. Priolo, and F. Iacona, Phys. Rev. B 69, 233315 (2004).

${ }^{35}$ D. J. DiMaria and J. R. Abernathey, J. Appl. Phys. 60, 1727 (1986).

${ }^{36}$ M. V. Fischetti, D. J. DiMaria, S. D. Brorson, T. N. Theis, and A. J. Kirtley, Phys. Rev. B 31, 8124 (1985).

${ }^{37}$ H. Krzyżanowska, K. S. Ni, Y. Fu, and P. M. Fauchet, Mater. Sci. Eng. B 177, 1547 (2012). 